\title{
The ICF Status and Plans in the United States
}

UCRL-CONF-216309

E. Moses, G. Miller, R. Kauffman

October 18, 2005

IFSA

Biarritz, France

September 4, 2005 through September 9, 2005 
This document was prepared as an account of work sponsored by an agency of the United States Government. Neither the United States Government nor the University of California nor any of their employees, makes any warranty, express or implied, or assumes any legal liability or responsibility for the accuracy, completeness, or usefulness of any information, apparatus, product, or process disclosed, or represents that its use would not infringe privately owned rights. Reference herein to any specific commercial product, process, or service by trade name, trademark, manufacturer, or otherwise, does not necessarily constitute or imply its endorsement, recommendation, or favoring by the United States Government or the University of California. The views and opinions of authors expressed herein do not necessarily state or reflect those of the United States Government or the University of California, and shall not be used for advertising or product endorsement purposes. 
The headers will be insert by the Publisher

The headers will be insert by the Publisher

The headers will be insert by the Publisher

\title{
The ICF Status and Plans in the United States
}

\author{
Edward I. Moses, George H. Miller, and Robert L. Kauffman \\ Lawrence Livermore National Laboratory \\ P. O. Box $808 L-466$ \\ Livermore, CA 94551 U.S.A.
}

\begin{abstract}
The United States continues to maintain its leadership in ICF as it moves toward the goal of ignition. The flagship of the program is the National Ignition Facility (NIF) presently under construction at LLNL. Experiments had begun on the first four beams of the National Ignition Facility just at the time of the last IFSA Conference. Several new successful campaigns have been conducted since then in planar hydrodynamics and hohlraums as well as activating the VISAR diagnostic for equation of state experiments. Highlights of these results will be reviewed. Presently, the four beam experimental capability has been suspended while the first eight beams are being installed as the first step in building out the project. Meanwhile, much progress has been made in developing ignition designs for using NIF. An array of designs having several ablator materials have been shown computationally to ignite with energies ranging from the design energy to as low as $1 \mathrm{MJ}$ of laser energy. Alternative direct drive designs in the NIF indirect drive configuration have been developed by LLE. This wide array of design choices has increased the chance of achieving ignition sooner on the facility. Plans are now being developed to begin an ignition experimental campaign on NIF in 2010, a little over a year after completion of the facility. Other US facilities are also implementing improved capabilities. Petawatt lasers are now under construction at the University of Rochester and Sandia National Laboratory. The Z pulsed power machine at Sandia National Laboratory is being refurbished to improve its performance. The ongoing research program at the OMEGA laser at the University of Rochester and the Z machine at Sandia National Laboratory as well as at the Nike, Trident and Janus lasers remain strong, performing experiments supporting the NIF ignition plan and direct drive ignition. There also is an active program in the broader field of high energy density science on these facilities. These activities will be reviewed here as well as presented in talks throughout the conference.
\end{abstract}

\section{Introduction}

The United States Inertial Confinement Fusion (ICF) Program is developing both the direct and indirect drive approach utilizing lasers and pulsed power devices. The major emphasis is on obtaining ignition on the National Ignition Facility (NIF) presently under construction at Lawrence Livermore National Laboratory (LLNL) [1]. A plan is being developed called the National Ignition Campaign (NIC) to begin the first ignition experiments on NIF in 2010. In addition, the US is developing new capabilities for future applications. Short pulse facilities are being constructed at the Laboratory for Laser Energetics (LLE) at the University of Rochester and at Sandia National Laboratory (SNL) and capability is also being developed for implementation on NIF. High average power laser technology for future energy applications is being developed at the Naval Research Laboratory (NRL) and at LLNL. 


\section{Direct Drive}

Direct drive ignition target designs have been developed that calculate to have good performance making them attractive alternatives for NIF ignition experiments [2]. The NIF is being activated as an indirect drive facility and conversion to a direct drive facility is not planned before 2013. In order to perform direct drive ignition experiments sooner, LLE has developed concepts for direct drive experiments in the indirect drive configuration. These designs, called polar direct drive (PDD), are illustrated in Fig. 1. In the first concept, shown in Fig. 1a, half of the beams are repointed toward the midplane on the capsule [3]. By controlling the laser pointing, spot size, and pulse shapes, Targets can be designed that calculate to ignite. In simulations of PDD implosion, a gain of 35 is obtained with 1 MJ of laser energy as shown in Fig. 2. Although these ignition designs calculate to ignite, tuning the beams around the midplane is challenging. An alternative concept called the Saturn target has been developed [4]. This concept, shown in Fig. 1b, has a $\mathrm{CH}$ washer placed around the midplane. When irradiated, plasma from the washer expands and refracts laser light toward the midplane aiding in obtaining symmetric illumination. Both concepts are being tested in experiments on the OMEGA laser at LLE [5].

Progress continues on direct drive cryogenic implosion experiments at LLE. The main thrust is to extend experiments to low adiabat $(\alpha \sim 4)$ implosions [6]. The adiabat is controlled by pulse shaping of the $2.5 \mathrm{~ns}, 17 \mathrm{~kJ}$ pulse. The experiments use improved layering with DD ice roughness of $<6 \mu \mathrm{m}$ rms with the best layers having a roughness of $1.2 \mu \mathrm{m}$ rms. Using the high contrast pulses, core conditions are produced having fuel areal densities of $\sim 100 \mathrm{mg} / \mathrm{cm}^{2}$ and ion temperatures of $\sim 2$ to 3 $\mathrm{keV}$ [7]. Hydrodynamic simulations using the 2D code, DRACO, are consistent with the data when the ice roughness and target offset are included.

Complementary direct drive target designs are being developed by NRL [8]. The target adiabat is controlled by pulse shaping and adding a prepulse. In planar experiments, they have shown that the prepulse can reduce growth of Rayleigh-Taylor instabilities.

\section{Z Pinches}

SNL continues to make progress in developing $\mathrm{Z}$ pinches for ICF applications. Double ended hohlraums indirectly drive ICF capsules [9]. These targets have $\mathrm{Z}$ pinch wire arrays at two ends of a hohlraum. In the center section is a secondary hohlraum

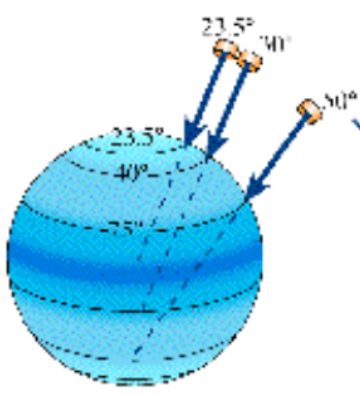

(1a)

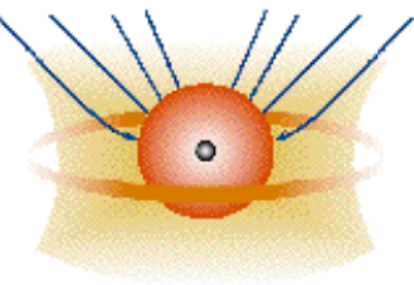

(1b)

Figure 1. Polar Direct Drive Concept showing PDD by repointing (1a) and the Saturn Concept (1b).

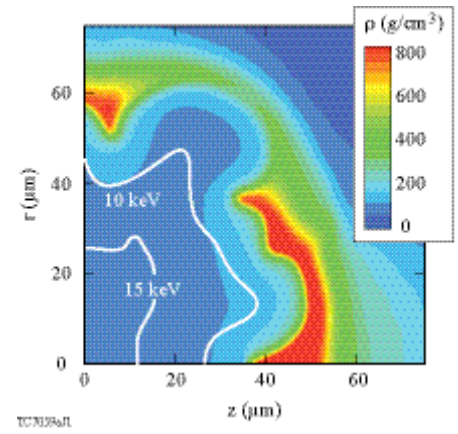

Figure 2. Calculated core conditions from a low adiabat direct drive implosion 
containing an ICF capsule. Radiation from the end hohlraum pinches heats the secondary hohlraum. P2 symmetry is controlled by varying the dimensions of the secondary hohlraum [10]. An example of the hohlraum tuning is shown in Fig. 3. This plot shows the P2 asymmetry, inferred from an imploded capsule, varying as a function of the secondary hohlraum aspect ratio, or length divided by radius. The data show that symmetric implosions are obtained for an aspect ratio of $\sim 1.65$. In other experiments, higher order symmetry control has been demonstrated by shimming the capsule.

Pulse shaping capability has also been demonstrated using nested wire arrays. A multi-shock radiation pulse using nested wire arrays is shown in Fig. 4 [11]. The radiation pulse from a nested array is compared with one from a single array. For the nested array, a foot pulse is generated followed by a first step and main pulse. Repeatability has been demonstrated with multiple shots plotted.

Implosion experiments with capsules absorbing high energy have been done using dynamic hohlraums. Dynamic hohlraums have a wire array collapse on a foam producing a high opacity pinch plasma that traps the radiation and serves as the hohlraum wall. The radiation can implode capsules placed in the foam. Previously, implosions of $\mathrm{CH}$ capsules have been reported [12]. Recently, capsules of Be coated over $\mathrm{CH}$ mandrils manufactured by General Atomics have been performed [13]. These DD-filled capsules absorb $\sim 45 \mathrm{~kJ}$ of $\mathrm{x}$-ray energy and have yields of $\sim 2 \times 10^{11}$, over half of predicted 1D yield.

\section{National Ignition Facility}

The National Ignition Facility (NIF) is a 192 beam Nd-glass laser facility presently under construction at LLNL. When completed, NIF will produce $1.8 \mathrm{MJ}, 500 \mathrm{TW}$ of ultraviolet light making it the world's largest and most powerful laser system. The NIF facility layout is shown in Fig. 1. Details of the laser and building design can be found elsewhere [1, 14]. Begun in 1995, the Project is over 80\% complete. The buildings and the beam path enclosures are completed and nearly all of the subsystems are designed. The laser components are assembled and installed in pre-aligned modules called linereplaceable units, or LRUs. Over 5,700 LRUs need to be installed and commissioned. Completion of the Project involves primarily the assembly, installation, and commissioning of the LRUs and installing the supporting utilities and control systems.

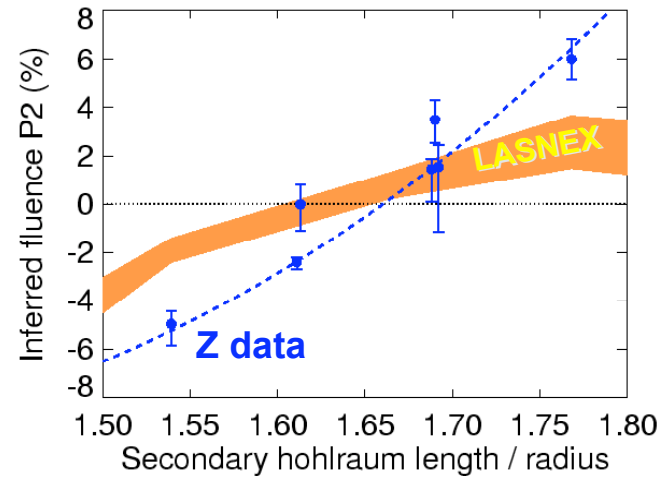

Figure 3. Demonstration of P2 symmetry control in a DEH

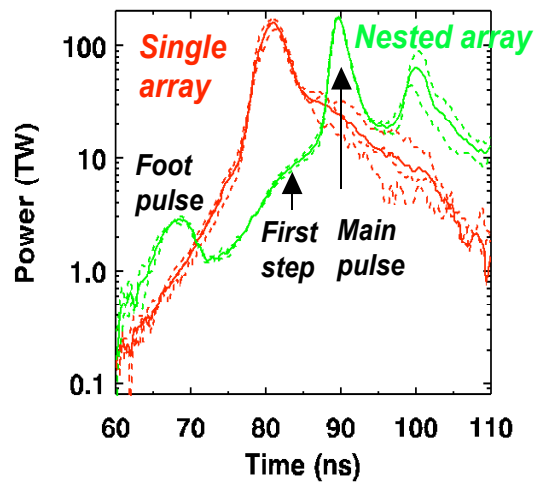

Figure 4. Demonstration of pulse shaping control in a nested array $\mathrm{Z}$ pinch. 


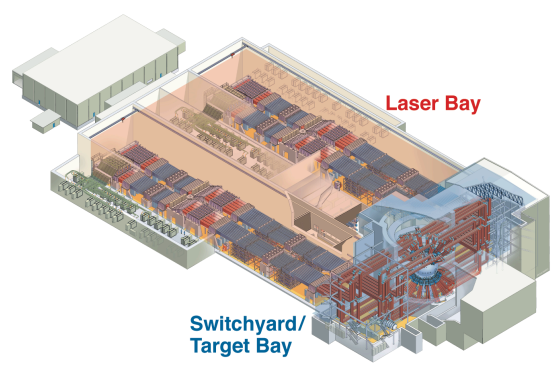

Figure 5. Layout of the National Ignition Facility

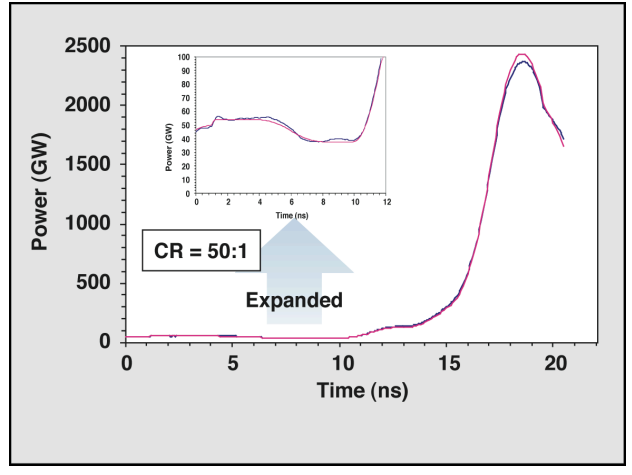

Figure 6. Example of an ignition pulse. The two curves are data from one NIF beam and the preshot prediction of the pulse.

The Project is being completed in two phases. In the first phase, the LRUs are being installed and beam lines activated in the laser bays to the switchyard wall. Beginning in 2007, the Project will begin to build out the beam lines to the target chamber. Project completion is planned for 2009. Presently, over 1000 LRUs have been installed, and one bundle of eight beams has been commissioned to the switchyard wall. During the activation, the bundle produced over $150 \mathrm{~kJ}$ of $1 \omega$ light. This is the highest energy pulse produced by a laser system using $4 \%$ of NIF's capacity.

In 2002, NIF activated a quad of four beams to the target chamber for NIF early light (NEL) experiments. Any one of the four activated NIF beams could also be directed to a separate experimental area, known as the Precision Diagnostic System (PDS), to fully characterize NIF's laser performance. On a beam line basis, all Project completion criteria and long-term functional requirements and primary criteria were demonstrated in PDS [15]. In separate PDS experiments, NIF produced $10.4 \mathrm{~kJ}$ of $3 \omega$ light and $11.4 \mathrm{~kJ}$ of $2 \omega$ light. This is equivalent to $2 \mathrm{MJ}$ and $2.2 \mathrm{MJ}$, respectively, for 192 beams. The laser demonstrated its capability required for ignition. Fig. 6 shows a $3 \omega$ ignition pulse. Along with the data, the predicted output from the Laser Performance Model is shown. The good agreement between experiment and prediction is consistent with ignition requirements for power balance.

The four beams were used for several sets of physics campaigns. A joint experiment by LLNL, LANL, and AWE studied the hydrodynamics of planar plasma jets in both 2-dimensional and 3dimensional geometries [16]. Joint experiments by LLNL, LANL, AWE, and CEA investigated hohlraum scaling and filling limits in halfraums $[17,18,19]$. The unique NIF geometry of multi-keV laser energy irradiating halfraums from a single direction allowed geometries that could easily be modeled in 2D radiation-hydrodynamics codes. In another experiment, beam propagation was studied through underdense plasmas showing the effectiveness of beam smoothing on controlling filamentation [20].

\section{Indirect Drive - National Ignition Campaign}

Advances have been made in indirect drive target designs with emphasis on developing more efficient hohlraum coupling and capsules that ignite with less absorbed energy [21]. Hohlraum designs now use mixtures of materials to increase opacity and reduce absorption by the hohlraum walls. Also, end shields have been added that reduce losses through the laser entrance holes and allow for a shorter hohlraum. These changes increase by $\sim 40 \%$ the coupling of laser energy to capsule absorbed $\mathrm{x}$-ray 

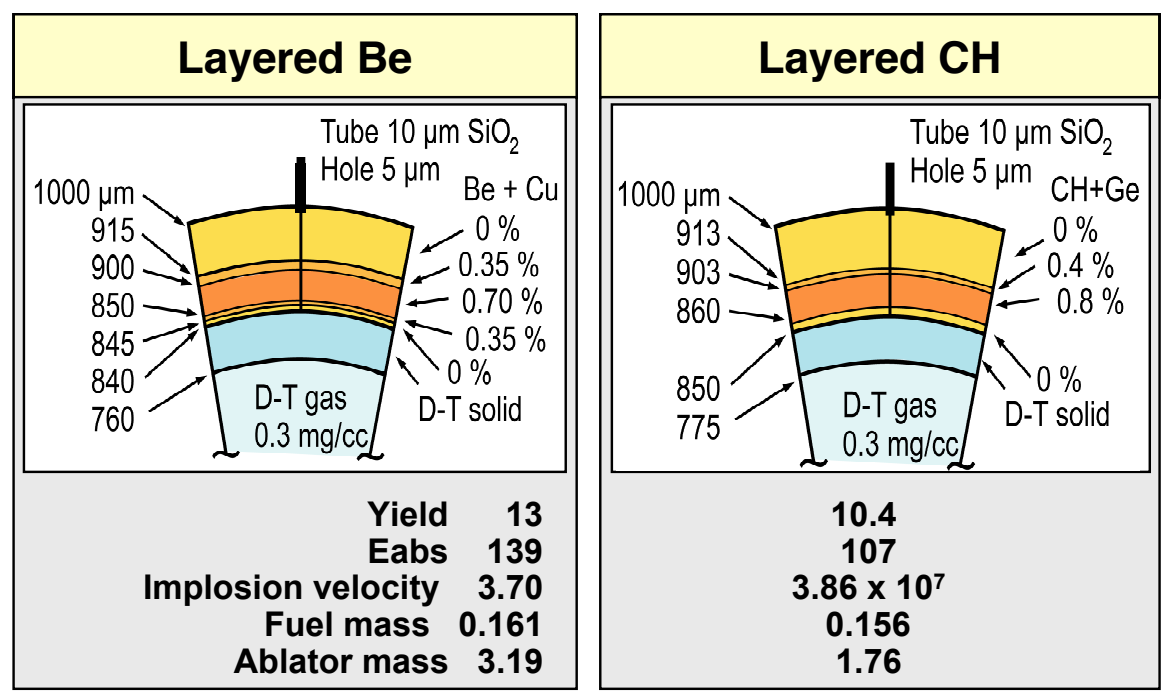

Figure 7. Two capsule designs that calculate to ignite with about $1 \mathrm{MJ}$ of laser energy.

energy. Two capsule designs have been developed that ignite with about $1 \mathrm{MJ}$ of laser energy. Diagrams of these designs are shown in Fig. 7. The designs have graded-doped Be, or CH, ablators. The dopant improve the hydrodynamic stability and manages the x-ray preheat. Each ablator has advantages and issues for target performance and manufacturing.

An integrated plan called the National Ignition Campaign (NIC) has been developed to integrate the activities required to prepare for ignition experiments. The goal of NIC is to begin ignition experiments in 2010 after the NIF Project is completed in 2009. Significant effort is required after the end of the Project to prepare for these experiments. The plan integrates a number of subsystems with the target physics and NIF operations into a multiyear effort culminating in the initial ignition experiments in 2010. These subsystems include diagnostics, user optics, cryogenic target capability, and personnel and environmental protection systems. The 2010 ignition experiments begin using laser energy of $\sim 1$ MJ with the energy ramping up to the full $1.8 \mathrm{MJ}$ in 2011. A pre-ignition campaign is planned at the beginning of 2010 to study the energetics, symmetry, ablator performance, and shock timing to optimize target performance.

\section{Target Fabrication}

Capsule designs that ignite at lower energy have placed new requirements on target fabrication. Both designs use graded dopants and have challenging surface finish requirements. Graded $\mathrm{Cu}$ doped $\mathrm{Be}$ capsules have been made at NIF scale by sputter deposition [22]. Example of a five layer $\mathrm{Cu}$-doped Be capsule is shown in Fig. 8. The capsule is manufactured by varying the relative sputter rate of $\mathrm{Cu}$ as a function of time. General Atomics has polished Be capsules, as shown in Fig. 9, to smoothness that nearly meet the surface finish requirements for ignition. General Atomics has also made graded $\mathrm{Ge}$-doped $\mathrm{CH}$ capsules that meet surface specifications. Further work continues on sputtered $\mathrm{Be}$ capsules in characterizing and minimizing voids in sputtered Be. 


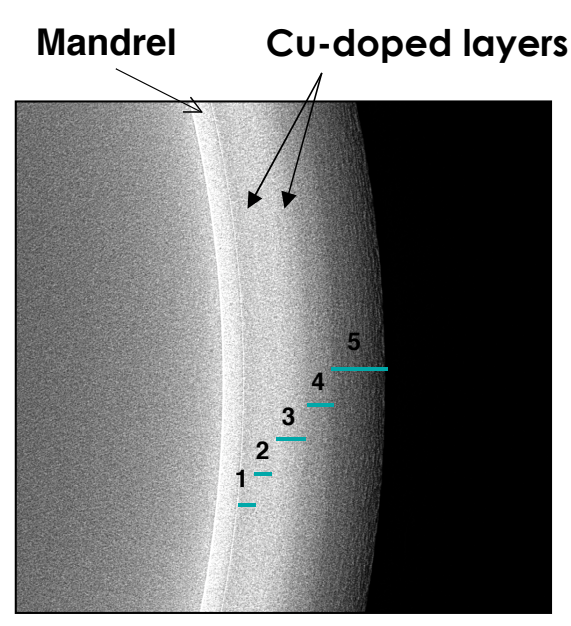

125 microns

Figure 8 Example of a graded $\mathrm{Cu}$ doped Be capsule

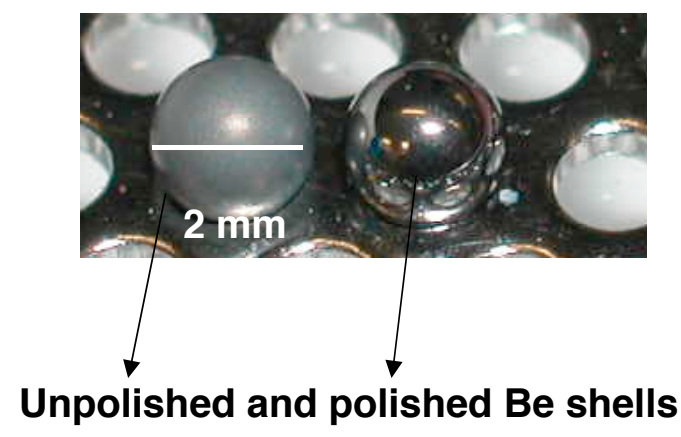

Figure 9. Comparison of Be capsules before and after polishing

The baseline for NIF is to fill capsules using fill tubes and layer and characterize at the facility. Filling capsules with DT using fill tubes of nearly the dimensions specified for NIF has been demonstrated. Layering in Be shells has been characterized by x-ray radiography. Finally, Hohlraums made of multilayer mixtures of uranium and gold have been manufactured by General Atomics that have low oxygen content. These have been shown to improve $x$-ray confinement efficiency in experiments at OMEGA.

\section{New Capabilities}

While NIF is the centerpiece of the US effort in ICF, incremental progress and new capabilities are being developed in various US laboratories. The Z machine at SNL is planned for a refurbishment to improve its reliability and performance [23]. Planned to be completed by 2007, the refurbishment should increase the delivered current by $\sim 30 \%$, which corresponds to $\sim 70 \%$ increase in energy. In addition, the Z backlighter (ZBL) laser [24] is being upgraded by adding short pulse capability for for flash radiography capability. Initially, the short pulse capability will be implemented in an offline chamber in 2006 and integrated with $\mathrm{Z}$ after the refurbishment.

The OMEGA EP (enhanced performance) is under construction at LLE [25]. Four new beam lines are being built in a new building at LLE. The beam lines use the NIF multi-pass architecture. Two of the beams will have long pulse capability in a new dedicated target chamber. The two other beams will have short pulse capability and will be used for radiography sources in the separate target chamber, or for radiography and fast ignition experiments in the present OMEGA target chamber. OMEGA EP is planned for completion in 2007.

Plans for developing advanced radiographic capability on NIF are also being developed. A conceptual design has been done for converting one quad of four NIF beams to short pulse for radiography applications. The design modifies the front end of the laser to produce a chirped pulse. The beams are passed through a pulse compressor in the target area and inserted in the target chamber using the direct drive ports. A schedule for converting one beam is presently being developed. Eventually more beams could be converted to support fast ignition capability. 
For fusion energy applications two high repetition rate laser systems are being developed. One system at NRL uses $\mathrm{KrF}$ technology [26]. The facility operates at a $5 \mathrm{~Hz}$ repetition rate. It has produced $500 \mathrm{~J}$ in a 500 shot operation mode. At LLNL, a diode-pumped, solid-state laser system is being developed [27]. It has produced $55 \mathrm{~J}$ per pulse for over $10^{6}$ pulses at $10 \mathrm{~Hz}$ operation. Both systems are continually upgraded to improve performance and further the technology development.

\section{Summary}

In summary, the US ICF Program is moving forward with its principal goal being the first ignition experiments in 2010. The NIF is scheduled for completion in 2009. An integrated NIC plan has been developed to begin credible indirect drive ignition experiments in 2010. Target designs have been developed that calculate to ignite using $\sim 1 \mathrm{MJ}$ of laser energy with an acceptable margin. New concepts for ignition designs have been developed that use the indirect drive configuration. If these concepts prove viable in OMEGA experiments, they could also provide an alternative path to ignition. Progress has also been made in indirect drive using $\mathrm{Z}$ pinches. Symmetry control and pulse shaping techniques have been demonstrated.

\section{Acknowledgments}

The contributions by the US ICF Programs provided by Robert McCrory, Keith Matzen, Joe Kilkenny, Juan Fernandez, Chris Barnes, and Stevc Obenschain are gratefully acknowledged. This work was performed under the auspices of the U. S. Department of Energy by the University of California Lawrence Livermore National Laboratory under contract No. W-7405-Eng-48.

\section{References}

[1] E. Moses, et al., Fusion Science and Technology, 43, p. 420, May 2003.

[2] P. W. McKenty, V. N. Goncharov, R. P. J. Town, S. Skupsky, R. Betti, and R. L. McCrory, Phys. Plasmas 8,2315 (2001).

[3] S. Skupsky, J. A. Marozas, R. S. Craxton, R. Betti, T. J. B. Collins, J. A. Delettrez, V. N. Goncharov, P. W. McKenty, P. B. Radha, T. R. Boehly, J. P. Knauer, F. J. Marshall, D. R. Harding, J. D. Kilkenny, D. D. Meyerhofer, T. C. Sangster, and R. L. McCrory, Phys. Plasmas, 11, 2763 (2004).

[4] R. S. Craxton and D. W. Jacobs-Perkins, Phys. Rev. Lett. 94, 095002 (2005).

[5] R. S. Craxton, F. J. Marshall, M. J. Bonino, R. Epstein, P. W. McKenty, S. Skupsky, J. A. Delettrez, I. V. Igumenshchev, D. W. Jacobs-Perkins, J. P. Knauer, J. A. Marozas, P. B. Radha, and W. Seka, Phys. Plasmas, 12, 056304 (2005).

[6] P. W. McKenty, T. C. Sangster, M. Alexander, R. Betti, R. S. Craxton, J. A. Delettrez, L. Elasky, R. Epstein, A. Frank, V. Yu. Glebov, V. N. Goncharov, D. R. Harding, S. Jin, J. P. Knauer, R. L. Keck, S. J. Loucks, L. D. Lund, R. L. McCrory, F. J. Marshall, D. D. Meyerhofer, S. P. Regan, P. B. Radha, S. Roberts, W. Seka, S. Skupsky, V. A. Smalyuk, J. M. Soures, K. A. Thorp, M. Wozniak, J. A. Frenje, C. K. Li, R. D. Petrasso, F. H. Seguin, K. A. Fletcher, S. Padalino, C. Freeman, N. Izumi, J. A. Koch, R. A. Lerche, M. J. Moran, T. W. Phillips, G. J. Schmid, and C. Sorce, Phys. Plasmas, 11, 2790 (2004).

[7] F. J. Marshall, R. S. Craxton, J. A. Delettrez, D. H. Edgell, L. M. Elasky, R. Epstein, V. Yu. Glebov, V. N. Goncharov, D. R. Harding, R. Janezic, R. L. Keck, J. D. Kilkenny, J. P. Knauer, S. J. Loucks, L. D. Lund, R. L. McCrory, P. W. McKenty, D. D. Meyerhofer, P. B. Radha, S. P. Regan, T. C. Sangster, W. Seka, V. A. Smalyuk, J. M. Soures, C. Stoeckl, S. Skupsky, A. Frenje, C. K. Li, R. D. Petrasso, and F. H. Seguin, Phys. Plasmas, 12, 056302 (2005).

[8] N. Metzler, A. L. Velikovich, A. J. Schmitt, and J. H. Gardner, Phys. Plasmas 9, 2050 (2002). 
[9] M. E. Cuneo, R. A. Vesey, J. L. Porter Jr., G. R. Bennett, D. L. Hanson, L. E. Ruggles, W. W. Simpson, G. C. Idzorek, W. A. Stygar, J. H. Hammer, J. J. Seamen, J. A. Torres, J. S. McGurn, and R. M. Green, Phys. Rev. Lett. 88, 215004 (2002).

[10] R. A. Vesey, M. E. Cuneo, G. R. Bennett, J. L. Porter Jr., R. G. Adams, R. A. Aragon, P. K. Rambo, L. E. Ruggles, W. W. Simpson, and I. C. Smith, Phys. Rev. Lett. 90, 035005 (2003).

[11] M. E. Cuneo, D. B. Sinars, D. E. Bliss, E. M. Waisman, J. L. Porter, W. A. Stygar, S. V. Lebedev, J. P. Chittenden, G. S. Sarkisov, and B. B. Afeyan, Phys. Rev. Lett. 94, 225003 (2005); M. E. Cuneo, Phys. Rev. Lett., to be published.

[12] C. L. Ruiz, G. W. Cooper, S. A. Slutz, J. E. Bailey, G. A. Chandler, T. J. Nash, T. A. Melhorn, R. J. Leeper, D. Fehl, A. J. Nelson, J. Franklin, and L. Ziegler, Phys. Rev. Lett. 93, 015001 (2004).

[13] J. Bailey, FO26.1, these proceedings.

[14] E. Moses in Inertial Fusion Sciences and Applications, Monterey CA, 2003, edited by B. A. Hammel, D. D. Meyerhofer, J. Meyer-ter-Vehn, and H. Azechi (ANS, La Grange Park, IL, 2004), p. 535.

[15] C. Haynam, WO16.2, these proceedings

[16] B. E. Blue, S. V. Weber, S. G. Glendinning, N. E. Lanier, D. T. Woods, M. J. Bono, S. N. Dixit, C. A. Haynam, J. P. Holder, D. H. Kalantar, B. J. MacGowan, A. J. Nikitin, V. V. Rekow, B. M. Van Wonterghem, E. I. Moses, P. E. Stry, B. H. Wilde, W. W. Hsing, H. F. Robey, Phys. Rev. Lett. 94, 095005 ( 2005).

[17] O. Landon, TuP2.3, these proceedings

[18] D. E. Hinkel; M. B. Schneider; H. A. Baldis; G. Bonanno; D. E. Bower; K. M. Campbell; J. R. Celeste; S. Compton; R. Costa; E. L. Dewald; S. N. Dixit; M. J. Eckart; D. C. Eder; M. J. Edwards; A. Ellis et al, Phys. Plasmas 12, 056305 (2005).

[19] J. Fernandez, TuO7, these proceedings

[20] Glenzer SH, Arnold P, Bardsley et al., Nuclear Fusion 44, S185-S190 (2004).

[21] J. D. Lindl, MP1.1, these proceedings

[22] A. Nikroo TuO9.3, these proceedings

[23] D. H. McDaniel, M. G. Mazarakis, D. E. Bliss, et al. In Proceedings of the Fifth International Conference on Dense Z-Pinches, Albuquerque NM, 2002 edited by J. DavisC. Deeney, and N. R. Pereira (AIP, Melville, NY, 2002), p. 23

[24] G. R. Bennett, O. L. Landen, R. F. Adams, J. L. Porter, L. E. Ruggles, W. W. Simpson, and C. Wakefield, Rev. Sci. Instrum. 72, 657 (2001).

[25] J. D. Zuegel TuPo7.33, these proceedings

[26] J. D. Sethian, M. Friedman, J. L. Giuliani, Jr., R. H. Lemberg, S. P. Obenschain, P. Kepple, M. Wolford, F. Hegeler, S. B. Swanekamp, D. Weidenheimer, D. Welch, D. V. Rose, and S. Searles, Phys. Plasmas, 10, 2142 (2003).

[27] C. Bibeau, TuO10.1, these proceedings 